\title{
Supplementary for: Implementing a sectional scheme for early aerosol growth from new particle formation in the Norwegian Earth System Model v2: comparison to observations and climate impacts
}

Sara M. Blichner ${ }^{1}$, Moa K. Sporre ${ }^{2}$, Risto Makkonen ${ }^{3,4}$, and Terje K. Berntsen ${ }^{1}$

${ }^{1}$ Department of Geosciences, University of Oslo, Oslo, Norway

${ }^{2}$ Department of Physics, Lund University, Lund, Sweden

${ }^{3}$ Institute for Atmospheric and Earth System Research / Physics, Faculty of Science, University of Helsinki, Finland

${ }^{4}$ Climate System Research, Finnish Meteorological Institute, Helsinki, Finland

Correspondence: Sara Marie Blichner (s.m.blichner@geo.uio.no) 


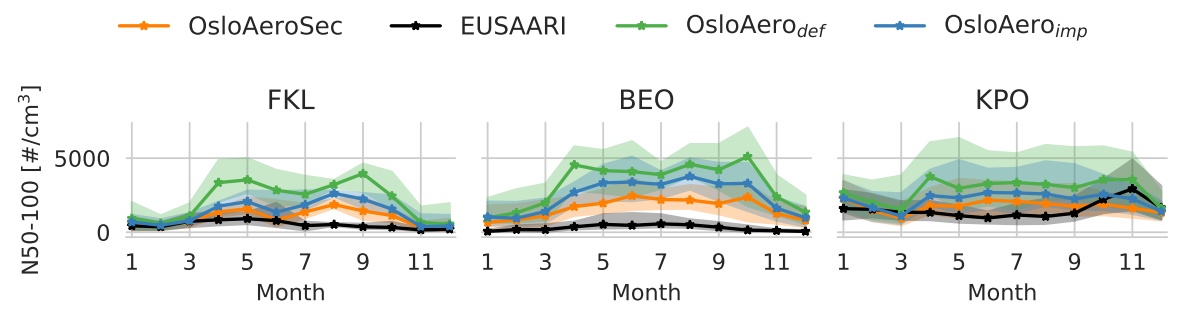

Figure S1. $N_{50-100}$ monthly median (solid line) and percentiles (shaded, 16th to 84th) for stations with high concentrations. The plot is the same as 4 , but displaying the full range of values which were cropped in figure 4. 

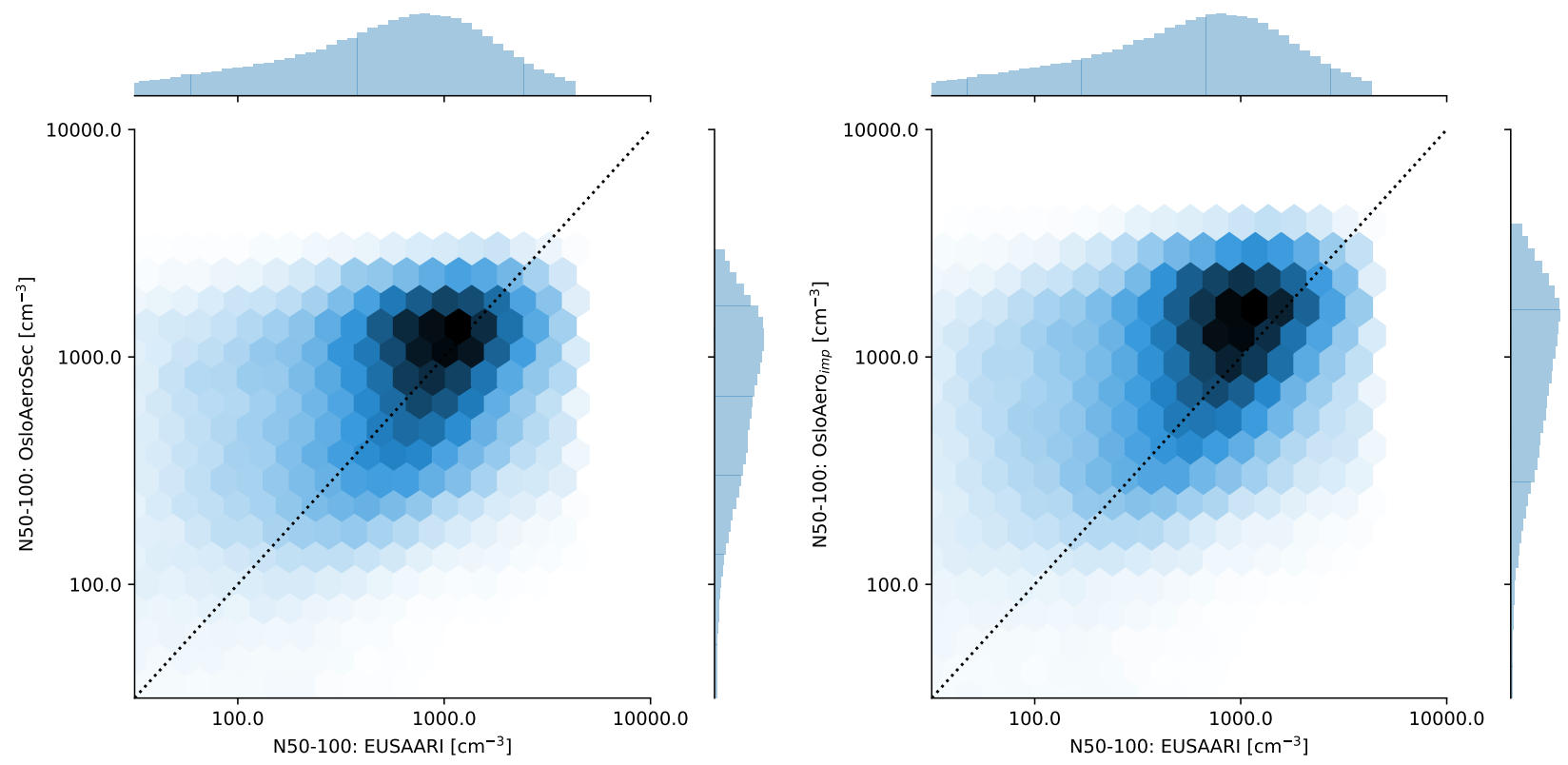

Figure S2. Two dimensional density distribution plots for $\mathrm{N}_{50-100}$ between modelled values (y-axis) and EUSAAR observations (x-axis). The left plot shows the relation for OsloAeroSec and the right for OsloAero ${ }_{i m p}$. 

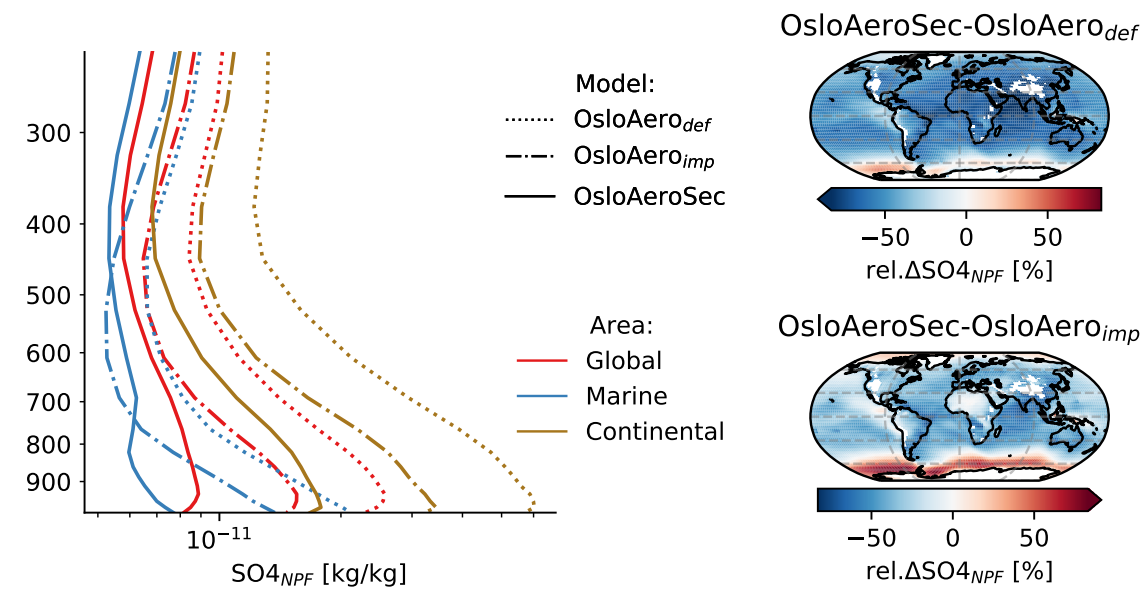

Figure S3. NPF particle mass in sectional scheme from $\mathrm{H}_{2} \mathrm{SO}_{4}\left(\mathrm{SO} 4_{\mathrm{NPF}}\right.$ ). The plot to the left shows the average profiles over regions (global, marine and continental). The plots to the right show the near-surface average difference between OsloAeroSec and OsloAero ${ }_{d e f}\left(\right.$ top$_{\text {) }}$ and OsloAeroSec and OsloAero ${ }_{i m p}$ (bottom). 

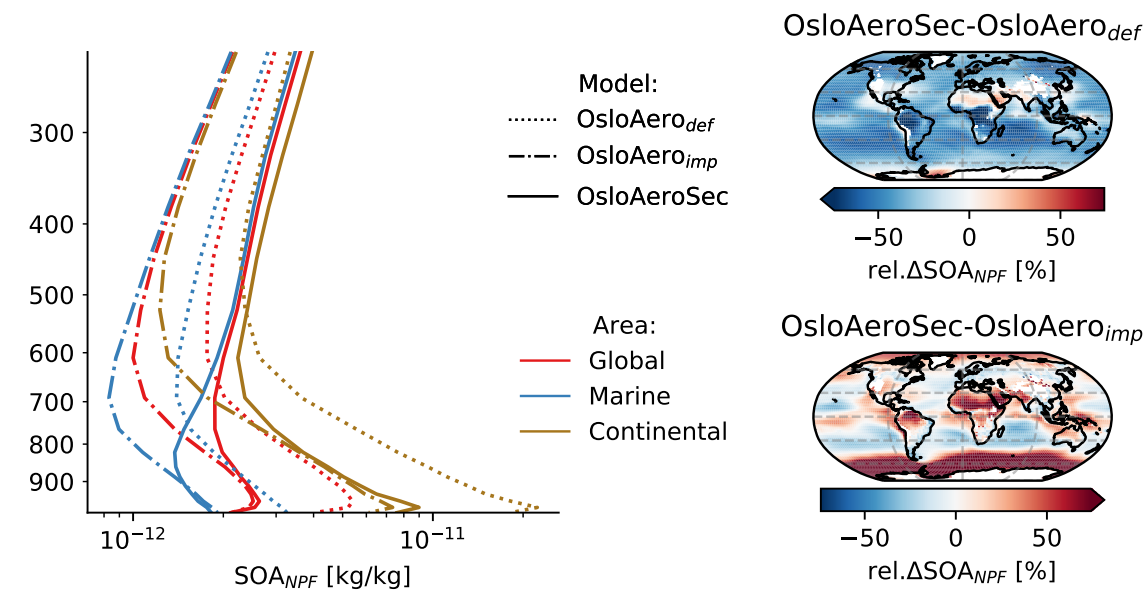

Figure S4. NPF particle mass in sectional scheme from $\mathrm{SOAG}_{L V}$ (SOA $\mathrm{SPF}_{\mathrm{NP}}$ ). The plot to the left shows the average profiles over regions (global, marine and continental). The plots to the right show the near-surface average difference between OsloAeroSec and OsloAero ${ }_{d e f}$ (top) and OsloAeroSec and OsloAero $i m p$ (bottom). 

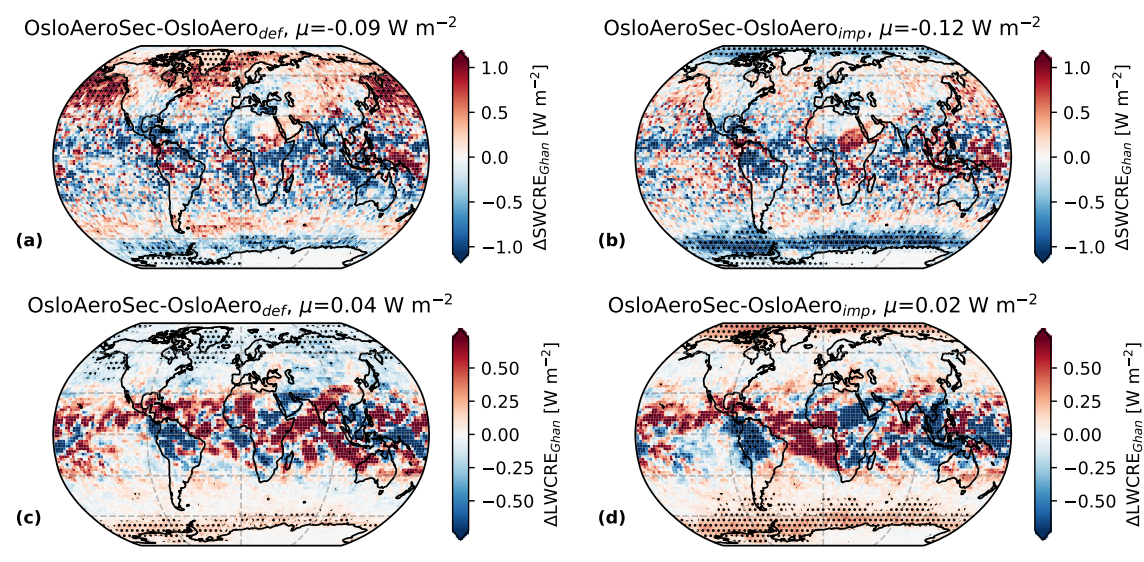

OsloAeroSec-OsloAero $_{i m p}, \mu=0.02 \mathrm{~W} \mathrm{~m}^{-2}$

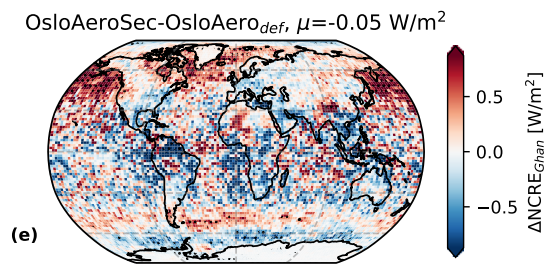

(d)

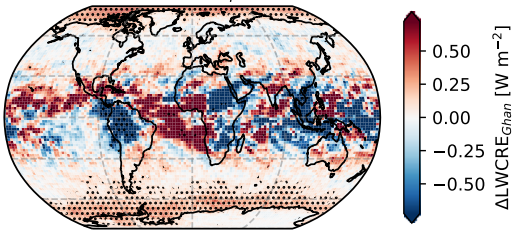

OsloAeroSec-OsloAero ${ }_{\text {imp }}, \mu=-0.11 \mathrm{~W} / \mathrm{m}^{2}$

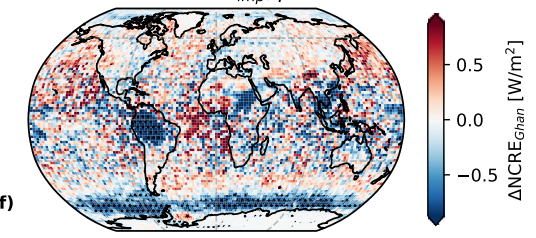

Figure S5. Difference in cloud radiative effect (CRE) for OsloAeroSec - OsloAero def $_{\text {(left) and OsloAeroSec - OsloAero }}$ imp. Short wave CRE (SWCRE, top), long wave CRE (LWCRE, middle) and net CRE (NCRE, bottom) 


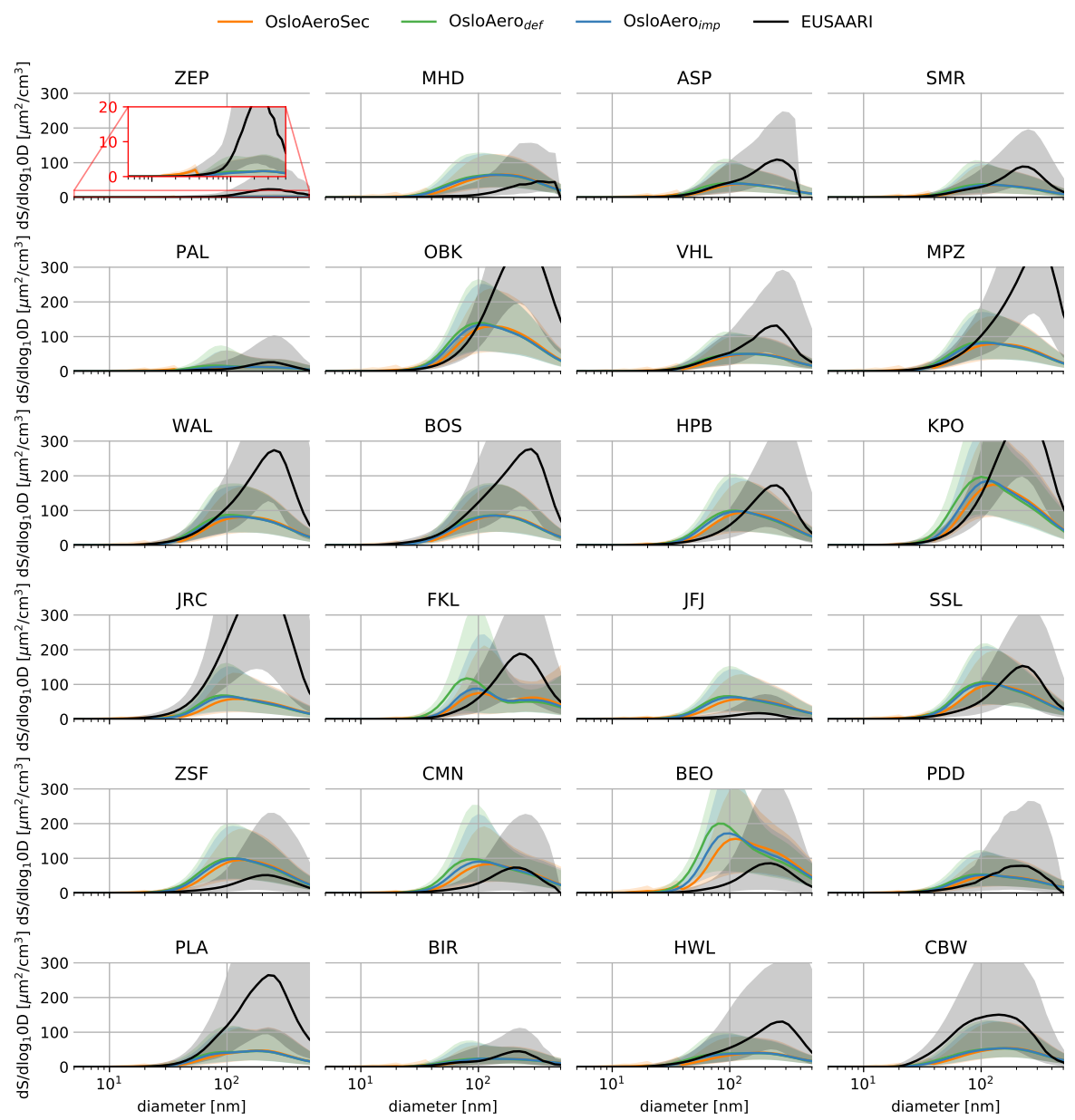

Figure S6. Median (solid line) particle surface size distribution and shading from 16th to 84th percentiles for observations and models. All data when and where observations are available is included. 


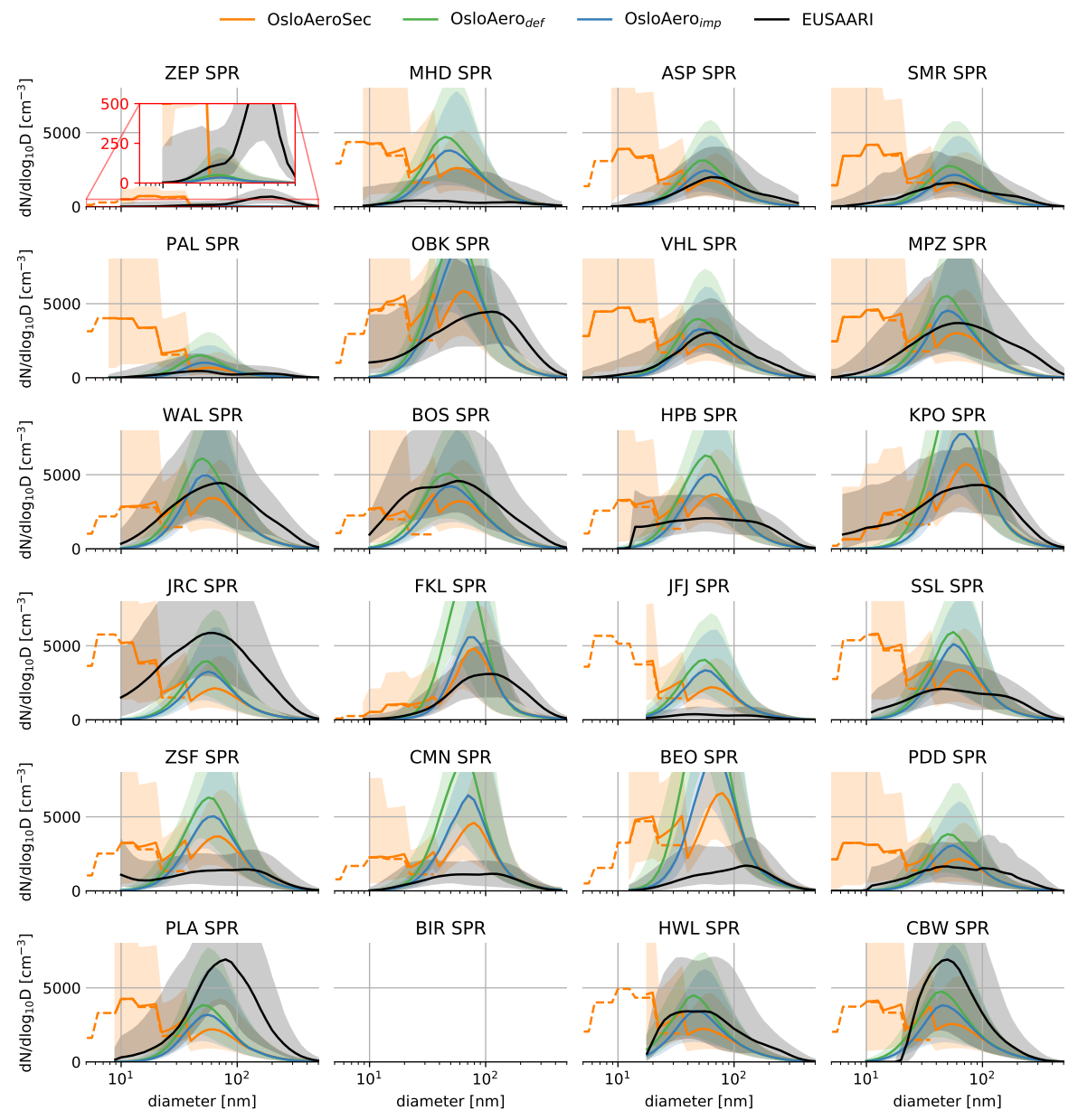

Figure S7. Spring: Median (solid line) and shading from 16th to 84th percentiles for observations and models for all valid datapoints. 


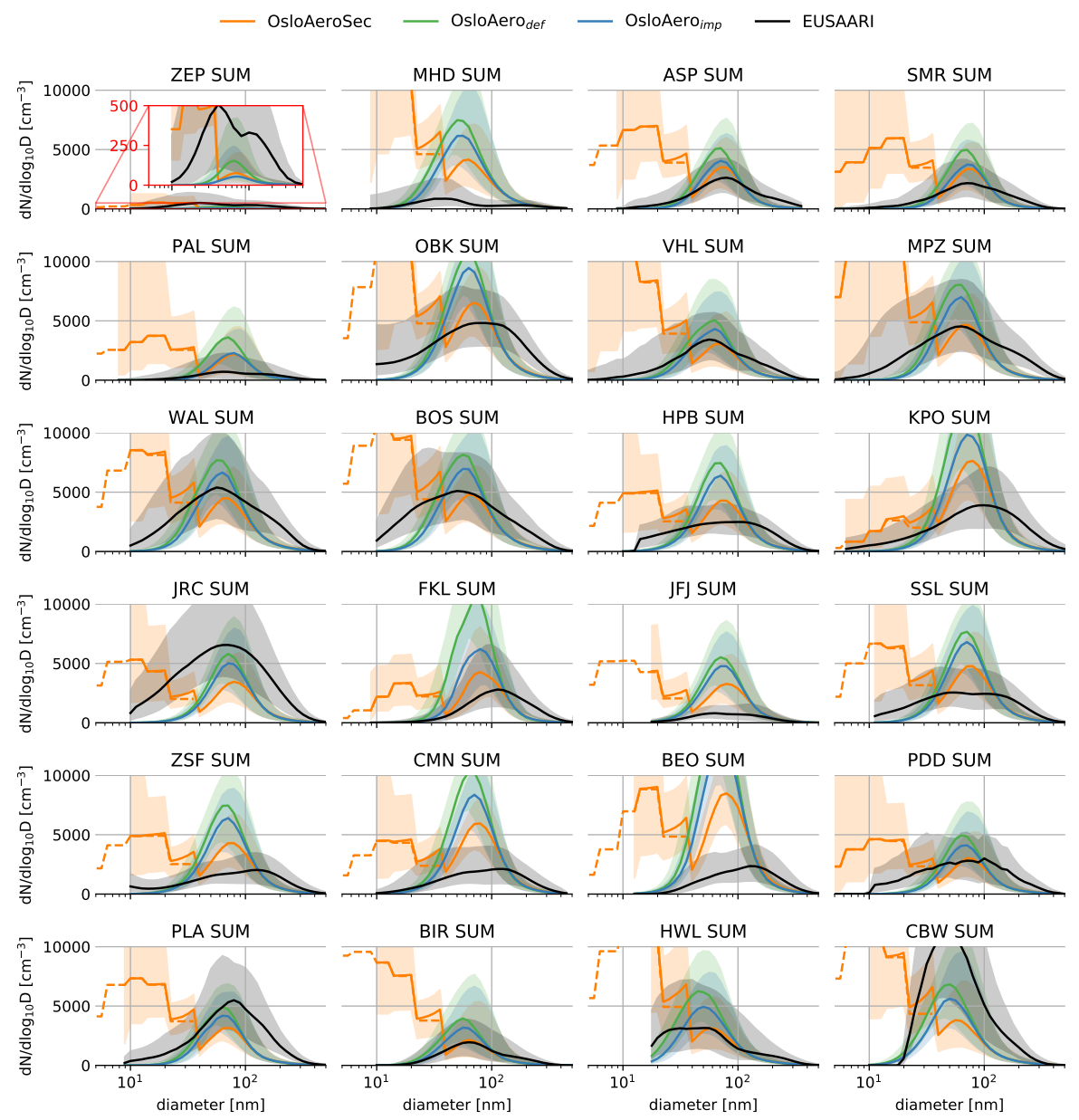

Figure S8. Summer: Median (solid line) and shading from 16th to 84th percentiles for observations and models for all valid datapoints. 


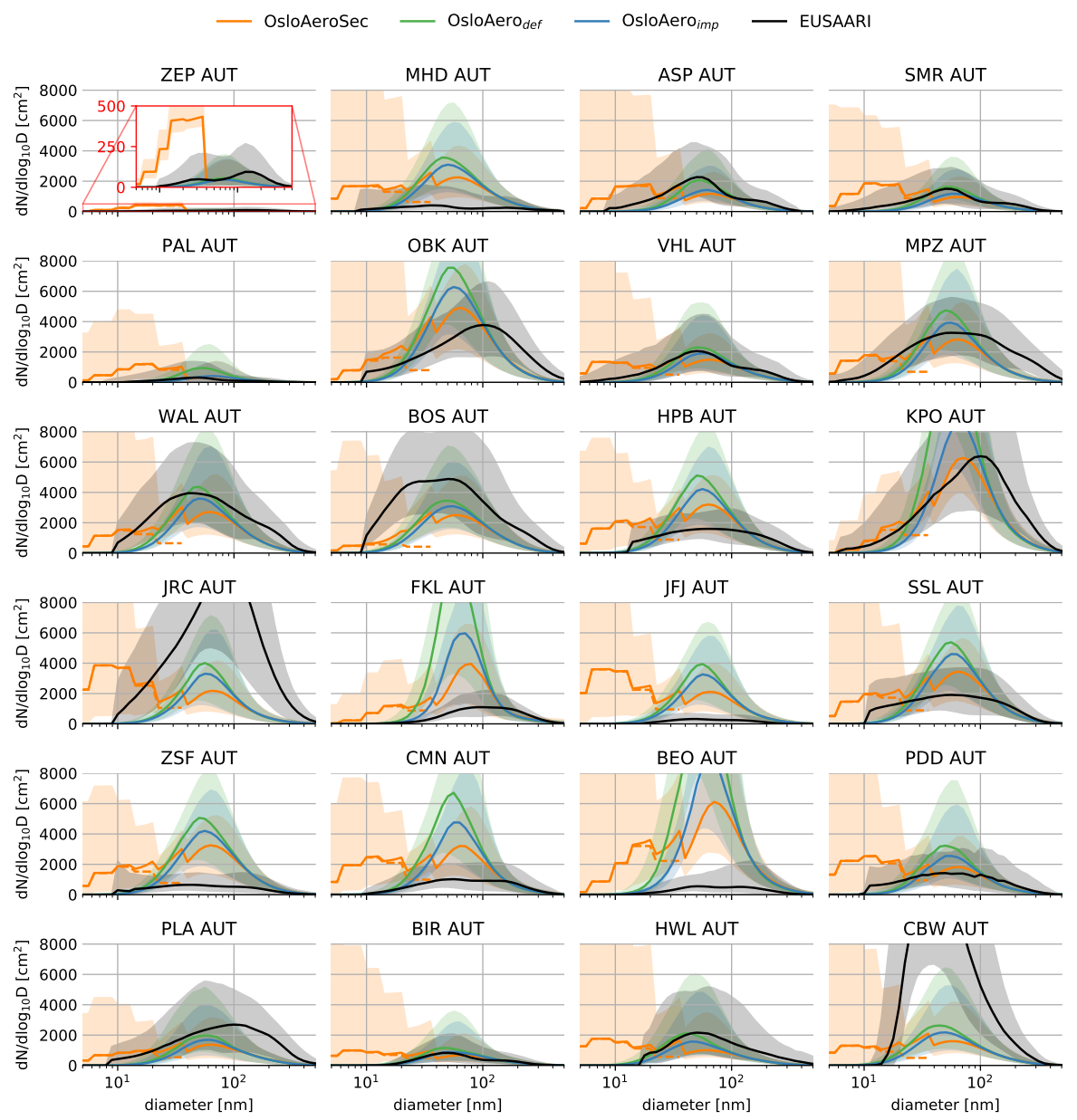

Figure S9. Autumn: Median (solid line) and shading from 16th to 84th percentiles for observations and models for all valid datapoints. 


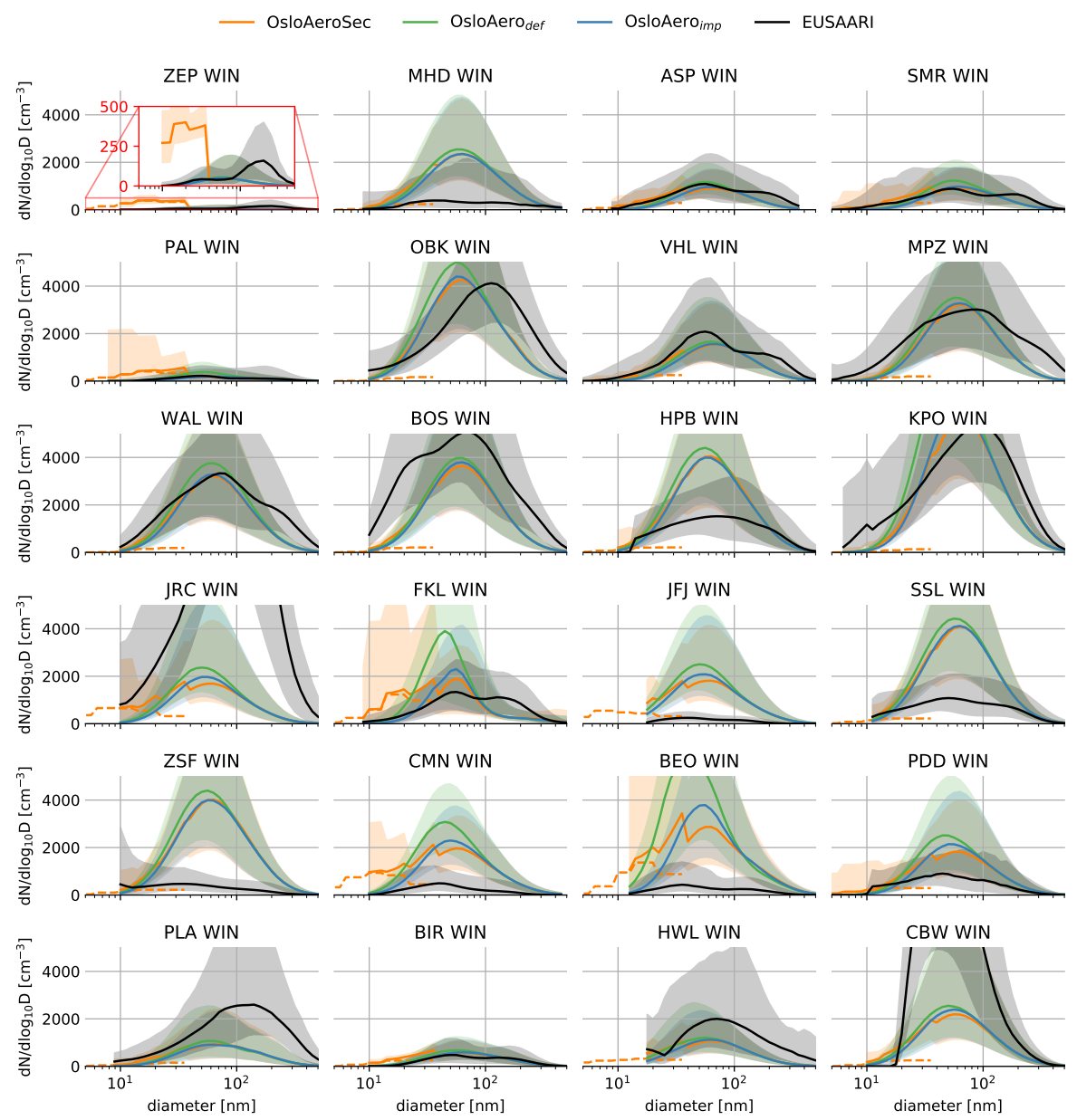

Figure S10. Winter: Median (solid line) and shading from 16th to 84th percentiles for observations and models for all valid datapoints. 


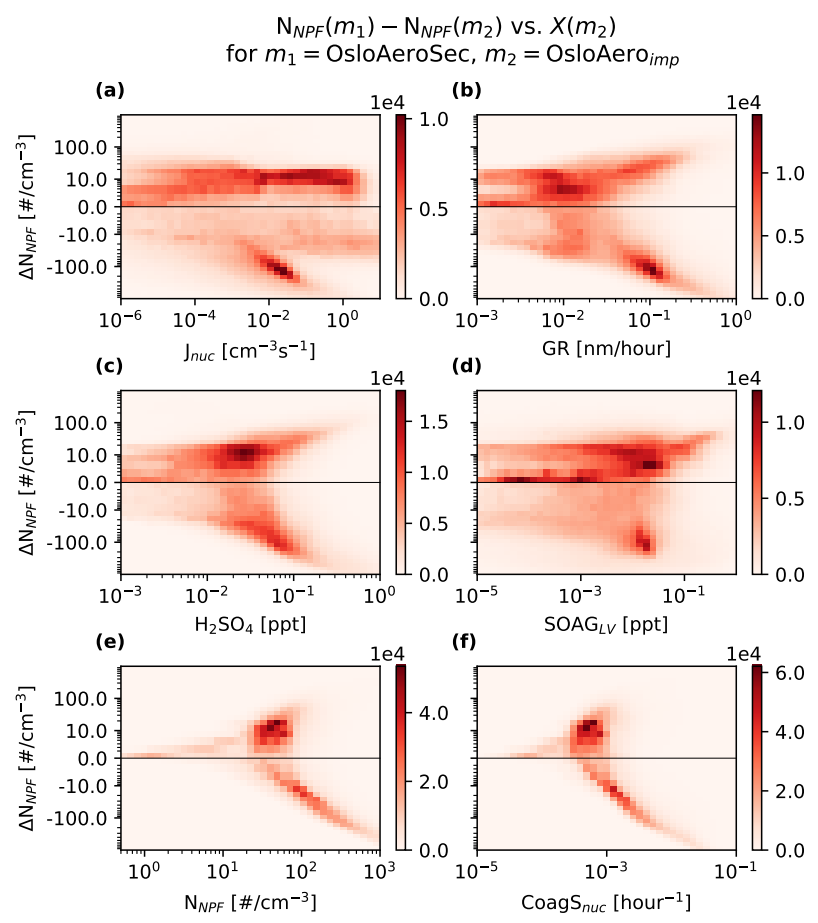

Figure S11. Same as 10, but comparing to OsloAero ${ }_{d e f}$, rather than OsloAero ${ }_{i m p}$. Two-dimentional histogram of the relation between various factors in the original model run OsloAero $i m p$, and the change in number of particles from NPF, $\mathrm{N}_{\mathrm{NPF}}$ between OsloAeroSec and OsloAero $_{\text {def }}$. The color shows the number of model grid cells which fall within the $\mathrm{x}, \mathrm{y}$-range using monthly mean files. Only grid cells below $100 \mathrm{hPa}$ are included. The y-scale is linear between \pm 5 . 

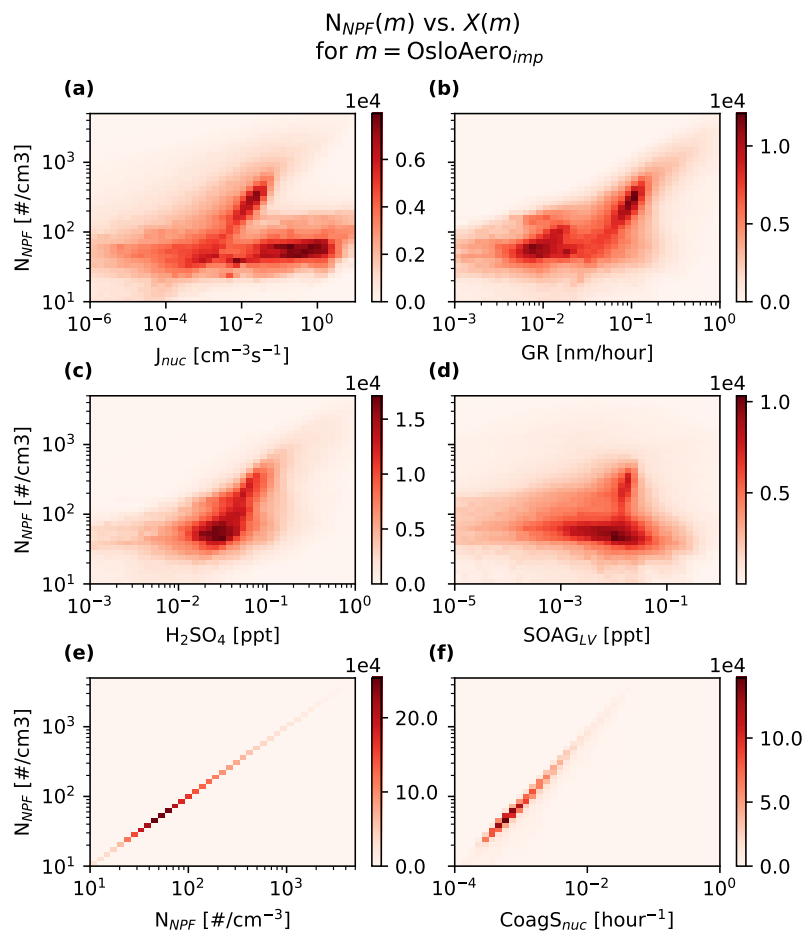

Figure S12. Two-dimensional histogram of the relation between $\mathrm{N}_{\mathrm{NPF}}$ and various factors in the OsloAero $i m p$ simulation. 10, The color shows the number of model grid cells which fall within the $\mathrm{x}, \mathrm{y}$-range using monthly mean files. Only grid cells below $100 \mathrm{hPa}$ are included. 


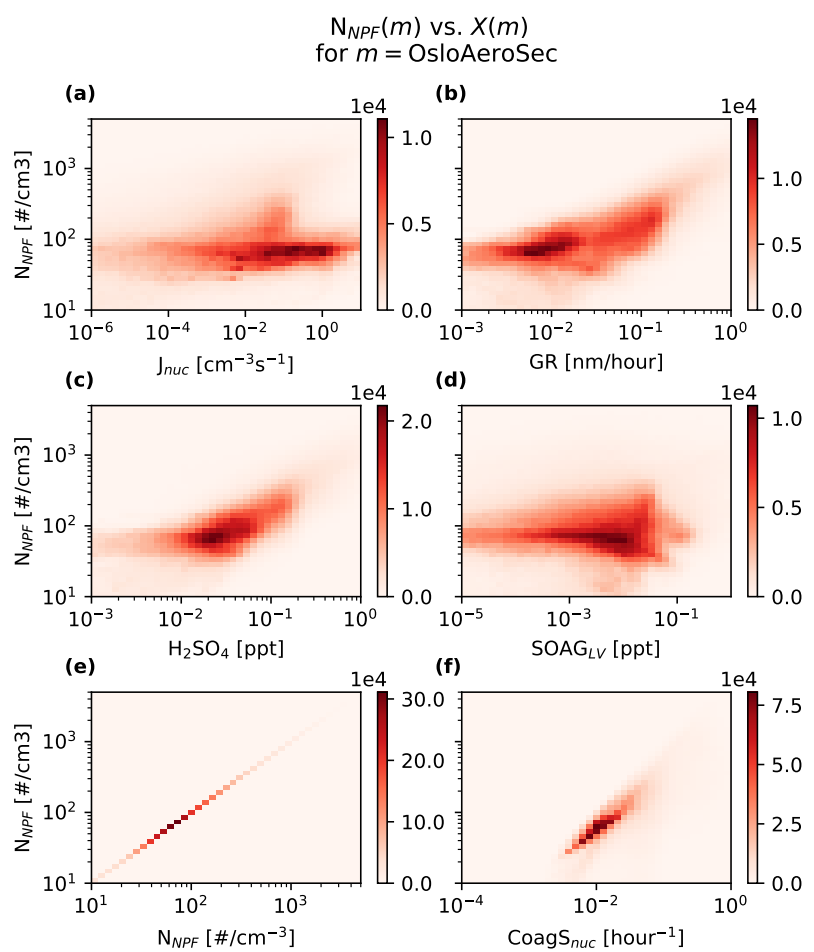

Figure S13. Two-dimensional histogram of the relation between $\mathrm{N}_{\mathrm{NPF}}$ and various factors in the OsloAeroSec simulation. 10, The color shows the number of model grid cells which fall within the $\mathrm{x}, \mathrm{y}$-range using monthly mean files. Only grid cells below $100 \mathrm{hPa}$ are included. 